\title{
Quality Assurance in Higher Education Institutions
}

\author{
Dr.. Jamal Fawaz Al-Omari \\ Associate Professor of Educational Administration \\ Princess Rahma University College, Department of Basic Sciences, Al Balqa Applied University, Jordan \\ Dr.Ayed Ahmad Al- Khawaldeh \\ Faculty of Educational Sciences, Department of Educational Administration, Mu'tah University
}

\begin{abstract}
The research is financed by Asian Development Bank. No. 2006-A171(Sponsoring information)
Abstract

The aim of the study is to indicate how quality control in Higher Education Institutions, and research quality and the concept of the proposals are identified in the application of quality in Higher Education Institutions, function and quality unit that implement the principles of total quality in Higher Education Institutions. The results of the study, said quality is the degree to match the characteristics of the product or service with the requirements established for that product, so it will keep the concept o of quality is the effort and activities that are being made by the consumer or the producer or any party to gain access to the best characteristics and qualities found in the commodity or service to meet the requirements for each features and characteristics that relate to the educational area ,which shows the excellence and achievement of the results to be achieved ," a translation of the needs of the student expectations to the specific characteristics as a basis for the dissemination of educational services and submitted to the students so as to match their aspirations, and thus seek comprehensive quality to prepare students certain features make them able to experience the abundance of information and the ongoing processes of change, and the tremendous technological progress, so this stage requires " a human being with certain specifications to accommodate all that is new and rapidly and deal with it effectively.
\end{abstract}

Keywords: Quality control, total quality management, Institutions of Higher Education

DOI: $10.7176 / \mathrm{JEP} / 13-3-04$

Publication date: January $31^{\text {st }} 2022$

\section{Introduction}

Given this accelerating quantitative increasing in the number of public and private universities, and the programs involved and that - sometimes - are put without studying the internal and external market needs, the pricing policies and methods of attraction, each university involves in marketing itself, compete with other universities and access to achieve quality outcomes, excellence and live up to international standards as possible. This distinction will not only draw a policy of the university to achieve them through the educational philosophy of global perspectives. Some of these starting points, learn to know, learn to work, learn to be, and learn to participate others through a systematic start from partial to whole, and not to exceed the first subject to another subject before its completion and application through the focus on following up and and accountability and depending on the quality and not the quantity.

To achieve this, we need to control the quality of education in the universities and apply the standards of the quality which are committed by the universities represented by the incomes and the outcomes of the university. This will not be achieved unless we establish Quality Control and accreditation unit in the university that will undertake the achievement of the comprehensive view which needs cooperation continuous and balanced with the legislators, managers and decision makers.

Quality is the power that feed teaching in universities effectively to achieve its goals which are required by the community in the light of specific criteria which is determined not only to measure the outcomes of the university learning and teaching, but it extends to reach the elements of providing teaching service in general and the faculty in particular.

The most prominent issue and problem faced by Higher Education - for example - the gap between the efficiency of the outputs of Higher Education and the needs of the labor market.

There is a program aims to enable the institutions of Higher Education to achieve the qualitative and quantitative balance between the outputs of the institutions of Higher Education and the requirements of the development in the Public and Private Sector via monitoring the structural changes in the economic structure and social mobility, then Higher Education institutions shall be provided with specific detailed information about the best orientation of the best programs and university's scientific specializations in order to guide the policies during the development of programs and admissions policies in line with the changes occur in social structure.

There are two views prevalent in the field of Higher Education. First: The policy of academic interest which deals with the concept of (science for science) and this means giving the university a unique situation based on the foundations of philosophy based on the importance of science for the development of access to knowledge, 
science, culture and deepen the study of academic and scientific specializations, and focus on the intellectual power and mental ability of a university student, scientific researcher and development of the mind.

The second point of view is the policy of community interest (Science for Development), which is based on that the developing countries facing civilization challenge, where these countries adopt the point of view that Higher Education is just a means but not an end, where Higher Education shall depend on community's need to several scientific specializations and oriented to serve the community and meet its needs.

The universities -at present time - face output disability of what is required from the local labor market such as experience and professional technical skills, despite their theoretical potentials which suit and compete in their level with the output of their counterparts of other universities. And therefore - as one of the researchers confirms - the problem of compatibility between the university requirements that ensure the quality of the scientific level and its internationally adoption, and labor market requirements that cannot be ignored because this market is considered as the main container for most of these outputs, where the inefficiency of these outputs to meet the needs of the labor market will make these outputs as enormous social and economic burden, as well as the loss of these human resources and all that invested in their development.(AbuDuqah,2004).

But the alternatives, which are proposed to balance between the outputs of education and the labor market must maintain a balance between meeting the requirements of the labor market or a part of them with maintaining the scientific quality and university's sobriety including bridging the gap between the outputs of universities and the needs of the labor market, while retaining the leadership of the university and its contribution to the development of labor market.

1-2 The problem of the study

The problem of the study is defined in answering the following questions:

First question: What is the concept of quality and service quality in Higher Education institutions?

Second question: What are the basic principles of quality systems?

Third question: What proposals to raise the quality of Higher Education?

Fourth Question: What are the main axes of the Adoption and Quality Control Unit in the university?

1-3 Objectives of the study:

Research seeks to achieve the following objectives:

1 - Identifying the Total Quality Management in education.

2 - Identifying the concepts of Total Quality Management in the educational process.

3 - Identifying the potential of application of total quality in education in the institutions of Higher Education.

1-4 Importance of the study

The importance of this study lies in the following:

1 - Improve and develop the educational structure of the university to be in line with the concept of total quality management.

2 - The study shows the importance of Total Quality Management as a way to improve the university educational system and its development.

3 - The study fits decision-makers in the Jordanian universities on how to implement Total Quality Management in the exercise of their administrative and technical works to serve the students and the community.

4 - This study contributes to improve the educational inputs and use them properly to suit the size of the goals and outputs required from the universities.

5 - Developing and improving educational programs to keep abreast of changes and international developments.

\section{Theoretical literature}

A study by (Badri, 2009) aimed to measure the degree of application of Total Quality Management at the University of Yarmouk from the standpoint of administrative leaders. In order to achieve this goal, the researcher developed a questionnaire by reference to the theoretical literature and previous studies, which consisted, after submitted to a panel of arbitrators, from (48) items distributed on five areas which were distributed to a sample of (68) administrative leaders including deans of faculties, heads of departments and directors of departments and centers. The study found that the degree of implementation of Total Quality Management at the University of Yarmouk in the view of administrative leaders was applied at medium degree. The study found that there were no statistically significant differences at the level of significance $(0.05 \leq \alpha)$ Attributed to the variable of sex and Job title, and the presence of statistically significant differences attributable to the variable of the number of years of experience in favor of those who have an experience of 10 years and over. In light of these results, the researcher recommended that the presidency of the university shall develop strategic interim plans based on scientific research and studies to apply the concepts of Total Quality Management in the educational field in Jordan.

A study by (Ayoub ,2000) on "assessment of the effectiveness of the use of Total Quality Management in the development of the performance of universities in Jordan." In order to achieve this, the researcher chose a random sample consisted of (282) members of the faculty members in Jordanian public universities in order to gather information and then develop the questionnaire which consisted of (35) items. The study found a number of results 
including the existence of statistically significant differences between faculty members in assessing the effectiveness of the use of Total Quality Management in the development of the performance of Jordanian universities according to the University, and no statistically significant differences between faculty members in the assessment of the effectiveness of using comprehensive quality management system to enhance the performance of Jordanian universities according to university's rank.

(Soisson, 2000) developed a study entitled "Analysis of the Total Quality Management in universities from the perspective of the process, content and results). This study aimed to find out the effect of stringent efforts to implement Total Quality Management from the perspective of the content, process and results, where the study included the areas of: strategy, structure and systems, personnel, skills and shared values. The study concluded the following results:

- The outputs of total quality management, which compared with the ideals type of Maxnki, were deficient in most respects, as they scored a medium degree.

- Studying the stringent efforts of university compared to "Ship "s model" of total quality management, which did not affect the number of elements organized in a significant way.

- Analysis revealed the most important weaknesses points from the perspective of total quality process, which were represented by the low participation of the Chairman of the Board of Directors, the lack of the goals developed by the organization of goals and lack of control and diagnosis.

- Training and promotion are the two basic elements of any program of organizational change.

A study by (Burgan, 2001) on "Proposal for the application of Total Quality Management at the University of Hadramout." The study aimed to identify the conceptual framework of Total Quality Management as a recent trend in management, and identify how to apply the concepts in practice in Higher Education. The field and theoretical study concluded many of the results:

- The possibility of applying the principles of Total Quality Management in the university administration whereas the experiences of developed countries bear witness to that.

- The successful implementation of Total Quality Management requires the building of appropriate organizational culture to the idea of total quality management.

- Estimates of the faculty members and administrators towards a culture of Total Quality Management were not achieved properly.

- The students agreed to that there was a weakness in achieving the quality of university services in all areas and at the whole level of performance in accordance with ( $\mathrm{Z}$ test), despite the differences of their sex and faculties.

A study by (Kiyumi ,2003) on "The possibility of estimating the degree of application of some of the concepts of Total Quality Management in colleges of education in the Sultanate of Oman from the point of view of administrators and teachers in the college ".The study found the following results:

- The points of view of both administrators and teachers in colleges of education in the Sultanate of Oman were nearly identical in terms of the possibility of applying some of the concepts of total quality management, as the degree of applicability of certain concepts of Total Quality Management was "great" at all study areas except for the use of the scientific method where their points of view were "medium" from the point of view of both administrators and teachers.

- The results indicated the degree of difference in the possibility of applying some of the concepts of Total Quality Management in colleges of education, which were attributed to the variable of (academic qualifications), whereas difference was only in the area of (focus on the institution's message and decision-making, the use of scientific method, team work, ongoing training and continuous evaluation ). As for the field of (administrative and independency decentralization ) no statistically significant differences were found, and there were differences between the levels of (academic qualifications) variable for $\mathrm{PhD}$ holders in all areas except the area of (industry, decision-making) where the difference was in favor of BA holders.

- The results indicated that the degree of difference in the possibility of applying some of the concepts of Total Quality Management in education colleges, which are attributed to the variable of (career status) at the level of performance as a whole was in favor of the administrators compared to teachers, as well as attributed to the variable of (academic qualifications) at the level of performance as a whole in favor of $\mathrm{PhD}$ holders.

A study by (Dradkh, 2005) on the "degree of implementation of Total Quality Management at Al Balqa Applied University from the point s of view of educational leaders in the University" .The study aimed to know the views of educational leaders for the degree of implementation of Total Quality Management in Al Balqa Applied University, as it also aimed to find out the extend of the difference of views depending on job title, specialty, years of experience and academic rank. The study found the following results:

- The averages of the points of view of educational leaders for the degree of implementation of Total Quality Management at the of Balqa Applied University were "medium"..

- The existence of statistically significant differences in the views of educational leaders attributed to (Job Title) on the scale as a whole and the sub-areas, where the differences were in favor of the category of "Dean" with the exception of the fifth area (Information Management System), which was in favor of the categories (Dean, Vice 
Dean).

- The existence of statistically significant differences in the views of educational leaders attributed to the variable of (specialization) on the scale as a whole, and on the sub-areas in favor of the category of "specialty of the faculties of Human Sciences."

- The existence of statistically significant differences in the views of educational leaders attributed to the variable (years of experience) on the scale as a whole, where the differences were in favor of the category of ( 5 years and over).

- The existence of statistically significant differences in the views of leaders, educators attributed to the variable (academic rank) on the scale as a whole and the sub-areas whereas the differences were in favor of the category of "professor."

Comment in the literature background:

Through a review of literature background, Arabic and foreign, it is clear that the major axis is the quality in universities and colleges from the perspective of teachers, administrators and deans of colleges, while the current study deals with how to adjust the overall quality in Higher Education institutions in Jordan, in addition to that it is working to provide information that will help to develop and improve the performance of other Higher Education institutions and strengthen the role of officials, administrators and educators in achieving the objectives of these institutions.

\section{3-Methodology of the study}

The two researchers adopted the approach of the descriptive theory, which relies on the analysis of the concept of total quality and its modern trends , the requirements of its use in university education, the factors affecting it in the universities for the possibility of its application to improve the learning outcomes which will be reflected on the development of society and obstacles which face it , and then determine a vision for the development of university education in the light of using the concepts of total quality management.

To answer the questions of the study, the researchers have used the analytical theoretical method of the concept of Total Quality Management and the successes it scored in educational organizations for use in the development and improvement of university education in Jordan.

\section{4- Results}

1 - The results of answering the first question: what is the concept of quality and quality of service?

A - The concept of quality in Higher Education institutions?

Quality is a competitive advantage at the present time which is enjoyed by the administrative institutions, as the quality is one important aspect which it developed considerably as a result of environmental indicators. The term "quality" means the nature of the thing and the person, and the degree of its goodness (Tahir, 1998) .The term "quality" does not mean always "better" or "best", but it is a relative concept differs depending on the benefit gained by the customer, society, organization or other.

The term quality is an economic term which appeared according to industrial competitiveness and technological cooperation between the advanced industrial countries in order to control the quality of production and earn the trust of the market and the buyer, and that quality focuses on product excellence in any field. Quality is defined, within the concept of Total Quality Management(TQM), as a "meet and exceed the expectations of the beneficiary" (Barton \& Joan, 1991:7), and therefore the beneficiary determines the required quality that meets the desired satisfaction. Therein, the challenge and the difficulty lie in satisfying all beneficiaries who have different desires as they have different personalities whereas they come from different social classes.

"Donald Crump thinks that " quality is not a word that is just said , but it is an action we do, as the main element in the definition of quality lies in the service of customers (students), where quality does not lie in the size of the grants and budgets, and the numbers of faculty members, the number of books in the library, or the buildings and facilities at the university, but quality comes from attention to customer service (students), whether inside or outside the university. Crump believes that "the quality can be measured. Austin put two criterions to define quality, especially in Higher Education. The first criterion is that: the concept of quality in Higher Education focuses on the reputation of the institution or its sources. For example, the institution with the best facilities is often good. The second criterion: the definition of quality in education should be strengthened through the application of the philosophy of quality improvement (Zaidan, 1998).

The concept of quality in education is linked to all features and characteristics that relate to the educational area, which show the excellence and achievement of desired results, "as it is a translation of the needs of students to specific properties which are mainly the dissemination of educational services and submission them to the students so as to match their aspirations" (Al-Rasheed ,1995). And therefore the total quality seeks to provide the students with certain features to make them able to experience the abundance of information, the ongoing processes of change and considerable technological advance. Therefore, this stage requires "a person with certain specifications to accommodate what is new and rapidly and to deal with these specifications effectively" (Abu 
Malouh, 2001). This requires a major revolution in the role of the academic teacher and supervisor of any educational institution, whereas he is a trainer and guide and shall provide an educational environment that allows for freedom of expression, discussion and help students for collaborative and self-learning.

The traditional concept of the quality of university education has been associated with the checks, rejection, and focus on the final tests without reviewing the capacity, cognitive, logical, analytical, behavioral and motor skills, and therefore the traditional concept of quality in Higher Education transformed to the concept of quality assurance of Higher Education, which is based primarily on the necessity of selecting typical rates of the performance and building systems for quality management in Higher Education. With the difficulties of application, there was a great importance for the application of Total Quality Management in Higher Education which needs the participation of everyone to ensure the survival and continuity of the institutions of Higher Education, a way to improve the efficiency of the best performance (Al-Najjar, 2000). The quality of Higher Education means the ability of all the characteristics and product features to meet the educational requirements of the student, the labor market, society and all internal and external beneficiaries. We know very well that to achieve education quality we require to direct all Human Resources ,policies, systems, methods, processes and infrastructure in order to create favorable conditions for innovation and creativity to ensure that the educational product can meet all requirements that prepare the student to reach the level that we all seek to achieve (Al-Jisr, 2004 ).

The culture of quality and its programs lead to the contribution of each individual, administration, scientific unit, student and faculty to become part of this program, so the quality is the required force to push the system of university education effectively to achieve its goals and missions entrusted to it by the society and the parties which interested in university education.

Thus, we assume that the concept of quality varies according to the of the attitude of the individual, the society or organization, as the quality is the benefit resulting from the characteristics of the overall product or service provided to the community, the consumer and society, therefore, it is a social responsibility and the responsibility of everyone.

The above mentioned definitions refer to the relative point of view in of the beneficiaries, so that those definitions formed Transitions from the concept of "quality of the products", whether they are goods or services, to the quality of the organization, and then the quality of society as a whole and all its activities and its components. (Shabrawi, 2000) indicated that the concept of quality has transformed from:

- Control of defects to prevent defects (the principle of prevention rather than cure).

- The role of management transformed from the role of the worker, the Head of the workers and the Quality Department in the organization to the strategic role of quality handled by senior management.

- The concept of quality control (statistical control) transformed from the perspective of the product to the customer's perspective.

- Transformation from the interest in the product to the interest in the operations services and needs.

B - The concept of quality of service

Education is one of the most important services. The quality of service means the quality of provided services, whether expected or recognized service that identifies the consumer satisfaction or dissatisfaction, as some organizations make the consumer satisfaction as an important priority to enhance the quality of service.

There are three terms of the quality of service as mentioned by (Al-Masri, 2001):

1 - Expected Quality: which means what customers expect from the quality of the service provided to them, where these expectations influenced by some major factors such as marketing communications mix, customer needs, the reputation of the organization and the promises of the service provider.

2 - Experienced Quality: this includes the quality experienced by the customer during the actual experience of receiving the service, as affected by two factors which are the technical quality and functional quality.

3 - Recognized Quality: It means the quality approved by the customer when he compares the expected quality and experienced quality. If the expected quality was unrealistic (where the expected quality level is higher than the experienced quality), the experienced quality is low, while the recognized quality is high when the level of experienced quality equals the expected quality.

(Al-Najjar, 2000) Shows that the quality of service is measured by the duration of the service to meet the expectations of the customer, where the majority of services is offered during the presence of the customer and that means realizing the quality is not affected by the results of the service only, but the process of providing the service.

Measuring quality is affected to a large extent by the degree of integration and comprehensiveness of the definition of quality. Definition which links quality goals emphasizes the measurement of quality output, while the definition, which deals with quality as a standard term focuses on the characterization of quality as a normative basis for measurement, but in the case of measuring the quality in education, then it requires an emphasis on the importance of measurement based on the honest standards as possible. There are many stages of measuring quality in the educational field: 
1 - Measuring quality in terms of inputs.

2 - Measuring quality in terms of processes (procedures and practices).

3 - Measuring quality in terms of outputs.

4 - Measuring the quality according to expert's opinion.

5 - Measuring quality in terms of objective characteristics.

6 - The holistic perspective in the measurement of quality.

It is no doubt that the issue of quality in general, technical, higher and continuing education is one of the most important topics which focused on and adopted by the developed countries since a long period of time, whereas these countries have invested quality to become an important indicator and element in the development, research and competition. UNESCO, in its initiative of the year 2000 "Education for All", Identified several goals, where the sixth goal of UNESCO was to improve all aspects of education to make everyone able to reach a good level and all students can be distinct and that the students achieve measurable good results, especially in the capacity of literacy, numeracy and life skills over the life. This means that education and learning must provide learners with the knowledge, the tools and the ability to use acquired knowledge and skills with confidence, as well as the development of behavior which depends on the positive morals and values such as respect, the ability to communicate with others and know their rights. This is a high-quality education, which will lead to social and economic benefits (UNESCO, 1990).

- The results of answering the second question: What are the basic principles of quality systems? - Quality systems based on 3/2/ISO 9001 depend on seven basic principles: (Salti \& Elias, 1999)

1 - Organization: to ensure quality assurance the organization shall define the responsibilities of each person, his powers and regulatory interventions between him and the others, whereas the organization shall ensure that all works are correctly done.

2 - Documentation of the quality system: This includes the preparation of quality manual, procedures and work instructions, in other words, documentation of how to do all the work activities that affect the quality in the organization.

3 - Controlling the documentation of quality system: This includes the control of the development of this set of documents, review, approval, issuance, amendments to avoid the activities contrary to what is adopted.

4 - Keeping the records of quality: This aims to enable the organization to keep track of what happened in case of any problem, and to show that all necessary procedures and work instructions were followed, as well as keeping records of the quality of the external parties (such as customers, certification accreditation bodies), and internal bodies (such as internal auditors).

5 - Verification of the implementation of the activities covered by the quality system: This includes verification of the design, approvals, and checking of the product during the manufacturing process to ensure conformity of specifications, as well as monitoring the quality system to make sure it works well and the administration's review of this system to ensure its effectiveness.

6 - Identifying non-compliance cases and taking appropriate corrective actions: in case of any non-conformity related to quality system, the cause of the problems shall be determined and taking the appropriate corrective actions to prevent it from happening again and ensuring the effectiveness of these procedures.

7 - Improving communication, understanding and cooperation: This applies to the relationship between the departments, and the relationships within a single department, and which is intended to prevent errors by making sure that everyone knows what is required to him.

2 - The results of answering the third question: What are the proposals to raise the quality of Higher Education? These proposals are as follows:

learning the philosophy of the university.

It's important that all the Arab Universities shall determine a national and educational clear philosophy, so that this philosophy is consistent with the philosophy of community where it locates, and the philosophy of the nation its local community belongs to. This is achieved by defining a clear definition of the university, and then identifying a set of general and specific objectives. This is important because the university is accountable before the community in fulfilling the role expected of it in the field of Higher Education. The good university, according to educational standards, is the university which knows and recognizes four important issues:

1. Objectives that it seeks to achieve.

2. Its ability to achieve those goals successfully.

3. The general and specific objectives that must be maintained over time and which must be developed from time to time, or those that can be canceled and stop working out after a period of time.

The results of answering the fourth question: What is the possibility of applying TQM in higher education institutions?

The application of total quality management needs, in addition to previous requirements, the following: (Jawhar2:200:98) 
- Strengthening the decentralization to achieve greater efficiency in performing tasks - time management in a sound and scientific manner - to participate in the administration as a method of approach applied in the form of stages to total quality management learn the basic skills to enable them to function effectively. (Joseph, 1991) indicates an applied approach in the form of stages to total quality management, where participants learn the basic skills to enable them to function effectively. These stages are:

1. Phase Zero: At this stage, managers decide if they will benefit from overall improvements from the application of total quality management or not. This is the decision point for the application of total quality management.

2. Phase I: Planning and drafting: this stage includes formulate a vision of the educational system and its objectives, strategies and proposed policies as this stage requires to spread the spirit and concepts of total quality at all levels within the system, and choose some members to participate in the development and transfer system to the team spirit.

3. Phase II: Assessment and Evaluation: This phase involves the self-evaluation of the performance of individuals and appreciation of the regulatory system with a comprehensive survey of customer satisfaction of the beneficiaries -who are the students- and the university in general, in addition to the local environment.

4. Phase III: Application: It is the implementation phase of the philosophy of total quality management within the system at all administrative levels, through training initiatives specific to each individual and with the support of senior management to improve quality in the desired areas.

5. Phase IV: Share and dissemination of experiences: It is based on the phase of dissemination of experiences when succession in the application of total quality management.

\section{Recommendations}

- Dealing and addressing the obstacles which face the application of Total Quality standards in Jordanian universities in an attempt to reduce such obstacles and to overcome them so that the universities apply these standards in an effort to develop different management.

- Identifying the skills of graduates and observing their abilities and their knowledge of programs and disciplines they are studying, benefiting from the latest developments in scientific knowledge in this global village that its distances and dimensions shortened in the screen which has an area of half a square meter.

- $\quad$ Ensuring the full and exact extent of approved plans of study materials, programs and courses prescribed by the department concerned with what is required by the local labor market, regional and global developments , the latest scientific developments and most recently in the fields of knowledge which belongs to the program or specialist who graduated from the university.

- Hard work on the follow-up self-evaluation on academic departments, colleges, administrative departments and university facilities in compliance with the approved and comply with the valuable quality manual, distributed by the university on all its members to be as a guide.

- Evaluating the performance of students and their academic achievement in order to achieve learning outcomes successfully which predict the success goals of academic departments in the university and the satisfaction of the officials and the leadership of the university on the level of their performance and granting them all they were promised at the signing of labor contracts with the University.

- Reviewing samples of lectures and exams, especially for new faculty, and analyzing these samples and studying them to ensure the compatibility of the results of these studies with the study plans approved in the plan of the academic department and objectives to be accomplished and achieved.

- Finally, the preparation, follow-up and readiness to visit the Public Accreditation Committees and Private Accreditation Committees of the existing programs which operate in the university, as well as future programs which the university intends to develop.

\section{References}

1- AbuDuqah , S (2004) Assessment and its relationship to improving the quality of education in Higher Education programs, Scientific paper presented at the conference of quality in Higher Education in Palestinian universities, Al Quds Open University, which was held in the period between 3 to 5 July 2004, Ramallah, Palestine.

2- Sa'eed ,A (2007) The quality of university curriculums and the prospects of its development, a paper submitted to the National Symposium for the development of curricula and specializations organized by the Ministry of Education and Higher Education at the University of Aleppo, 30 to 31 May 2007.

3- Al-Hiyazi,M (2006) Proposals to increase the quality of university education in the Arab World, a paper submitted to the symposium accompanying the Sixth Conference of Deans of Faculties of Arts in Arab Universities.

4- Al-Jisr,S (2004) "Re-organization of private Higher Education" ,a paper submitted to the Workshop, held by the Ministry of Education and Higher Education ,the Directorate General of Higher Education, Beirut10$24 / 2 / 2004$ 
5- Zaidan.M. S, (1998) "Quality indexes in Egyptian Higher Education”, Journal of the Faculty of Education”, Al-Azhar Mosque 72.1998

6- Al-Salti,M.and Ilyas.S. (1999) “A practical guide for the application of quality management systems ISO9000. Dar Al-Fikr ,Damascus.

7- Al-Shabrawi,A.,(2000) "A practical guide for the application of Total Quality Management",Arab Media Company,Cairo.

8- Tahir,M. (1998) "philosophical and Intellectual frame of the introduction to Total Quality Management". Majalat Al-Edarah. V.30 (1),p. 77.

9- Mustafa,A (2007) "Quality Assurance Unit and the outputs of education", University of the Middle East for Graduate Studies, Amman.

10- Al-Masri,S. (2001) "Management and organization of hotel and tourist facilities" , Al-Dar Al-Jami'iyah, Alexandria.

11- Al-Najjar,F (2000) “ Total quality of university management”, Aterec for publication and distribution, Cairo.

12- The Ministry of Education and Higher Education, (2003), a system to ensure and improve the quality and performance of quality of Higher Education institutions in Palestine, paper submitted to workshop specialized on the assessment of quality and performance specialized in institutions of Higher Education and scientific research held at the University of Aleppo, Syria, 22 to 23 February 2003. 